\title{
Um estado de nervos...
}

Paula Gomes*

\section{RESUMO}

Introdução: Na prática clínica, o Médico de Família lida, frequentemente, com doentes com sintomas físicos para os quais não há uma causa orgânica ou mecanismos fisiológicos conhecidos explicativos. Estes doentes constituem um desafio, pela sobreutilização de consultas e cuidados de saúde, pela necessidade frequente de investigação clínica e pela difícil aceitação da inexistência de doença orgânica, levando à resistência ao tratamento e perpetuação de sintomas. Com a apresentação deste caso, pretende-se rever e ilustrar o papel do Médico de Família na abordagem do doente com perturbação conversiva, nomeadamente no diagnóstico, enquadramento biopsicossocial, relação médico-doente, objectivos terapêuticos, medidas farmacológicas, articulação com outras especialidades e follow-up.

Descrição do Caso: Mulher de 35 anos, funcionária de uma empresa de auto-serviço grossista, casada, com uma filha, na fase IV de Duvall, Graffar III.Antecedentes patológicos de perturbação depressiva/ansiosa. Inicia um quadro de paraparesia e hipostesia bilateral dos membros inferiores, de instalação súbita, recorrendo ao serviço de urgência, tendo sido internada. Após avaliação clínica e estudo neurológico, tem alta, sem melhoria sintomática, com o diagnóstico de perturbação somatoforme de mecanismo conversivo, no contexto de stress laboral. Desde então, a doente manteve contacto frequente com o Médico de Família, numa aliança médico-doente efectiva e em coordenação com as especialidades de Psiquiatria, Medicina Física e Reabilitação e Neurologia.

Comentário: Pela sua frequência, é necessária ao Médico de Família a aquisição de competências que lhe permitam a correcta identificação e abordagem dos doentes somatizadores. Torna-se basilar uma abordagem centrada no doente, com integração dos aspectos psicossociais e biomédicos. A principal modalidade terapêutica é a relação médico-doente, baseada na legitimização dos sintomas, num ambiente de confiança, empatia, suporte e acompanhamento contínuo, em articulação com os diferentes níveis de cuidados do sistema de saúde.

Palavras-chave: Perturbação Conversiva, Medicina Geral e Familiar

\section{INTRODUÇÃO}

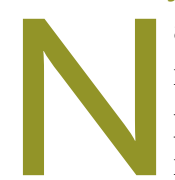

a prática clínica, o médico lida, frequentemente, com doentes com sintomas físicos, para os quais não há uma causa orgânica ou mecanismos fisiológicos conhecidos explicativos. Estima-se que cerca de $10 \%$ dos doentes que recorrem ao Médico de Família (MF), com um primeiro episódio de doença, cumpram critérios de somatização, constituindo as perturbações somatoformes cerca de um terço da morbilidade psiquiátrica nos Cuidados de Saúde Primários. ${ }^{1}$

Apesar da sua elevada prevalência, o relacionamento com o doente somatizador permanece um desafio na Medicina Geral e Familiar. Para além do tempo que ocupa (doentes com esta patologia podem consumir, aproximadamente, $50 \%$ do tempo do $\mathrm{MF}$ ), ${ }^{2}$ a sobreutilização dos cuidados de saúde acarreta elevados custos

* Médica Interna de Medicina Geral e Familiar Centro de Saúde de S. Mamede de Infesta (ULS Matosinhos). (nove a catorze vezes superiores à média). ${ }^{3}$ Para além disso, a difícil gestão dos pedidos frequentes de investigação médica, a reticência à aceitação da inexistência de doença de causa orgânica, a resistência ao tratamento e a cronicidade da patologia, podem despertar nos profissionais de saúde sensações de frustração, irritação e desconforto. Do ponto de vista do doente, o possível descontentamento com a atenção, compreensão, explicação e suporte terapêutico recebidos, leva à perpetuação dos sintomas, que não controlam voluntariamente e que lhes causam sofrimento significativo ou prejuízo no funcionamento social, ocupacional ou em outras áreas importantes. ${ }^{4-6}$

Pela sua maior acessibilidade e proximidade, o MF é, com frequência, contactado por estes doentes. As características inerentes à sua prática, tais como a abordagem centrada na pessoa, comunicação médico-doente efectiva e longitudinalidade, ${ }^{5}$ colocam-no numa posição privilegiada para contextualizar os problemas segundo um modelo biopsicossocial, integrando 
a dimensão cultural e existencial. O objectivo é centrar a raiz do problema, possibilitando um tratamento eficaz, assim como a articulação com os cuidados secundários.

Descreve-se o caso de uma mulher com 35 anos, com antecedentes de síndrome depressivo/ansioso, seguida regularmente nas consultas de medicina familiar, que inicia um quadro de paraparesia e hipostesia bilateral dos membros inferiores, de instalação súbita. O diagnóstico final foi o de perturbação conversiva.

Com a apresentação do caso, pretende-se rever o papel do MF na abordagem do doente com perturbação conversiva, nomeadamente no diagnóstico, enquadramento biopsicossocial, relação médico-doente, objectivos terapêuticos, medidas farmacológicas, articulação com outras especialidades e follow-up.

\section{DESCRIÇÃO DO CASO}

AMMC, sexo feminino, 35 anos, raça caucasiana, funcionária de uma empresa de auto-serviço grossista. É natural do concelho do Porto, passando a residir num concelho limítrofe a partir dos 20 anos. É casada desde há quinze anos e tem uma filha com onze anos, en- quadrando-se, a nível sócio-económico, na classe III de Graffar. Não tem hábitos tabágicos, etílicos e toxicológicos.

Salientam-se, dos seus antecedentes pessoais, os seguintes (ver biopatografia - Figura 1):

- Amaurose esquerda, por catarata congénita, em 1980, tendo sido submetida a cirurgia oftalmológica, com recuperação parcial da acuidade visual. Refere, posteriormente, diminuição progressiva da acuidade visual à esquerda, com amaurose em 2000.

- Gastrite crónica e hérnia do hiato, diagnosticadas em 1989.

- Hérnia discal L5-S1, com eventual compromisso radicular L5-S1 direito, diagnosticada em 2005, com episódios de lombociatalgia, mais intensa à direita.

- Antecedentes psiquiátricos:

- Depressão pós-parto em 1995.

- Síndrome depressivo major recorrente, com início em 1995. Agravamento desde 2005.

- Medicada, habitualmente, com fluoxetina $20 \mathrm{mg} /$ /dia.

É seguida pelo MF de forma regular, com necessidade frequente de consultas não-programadas no contex-

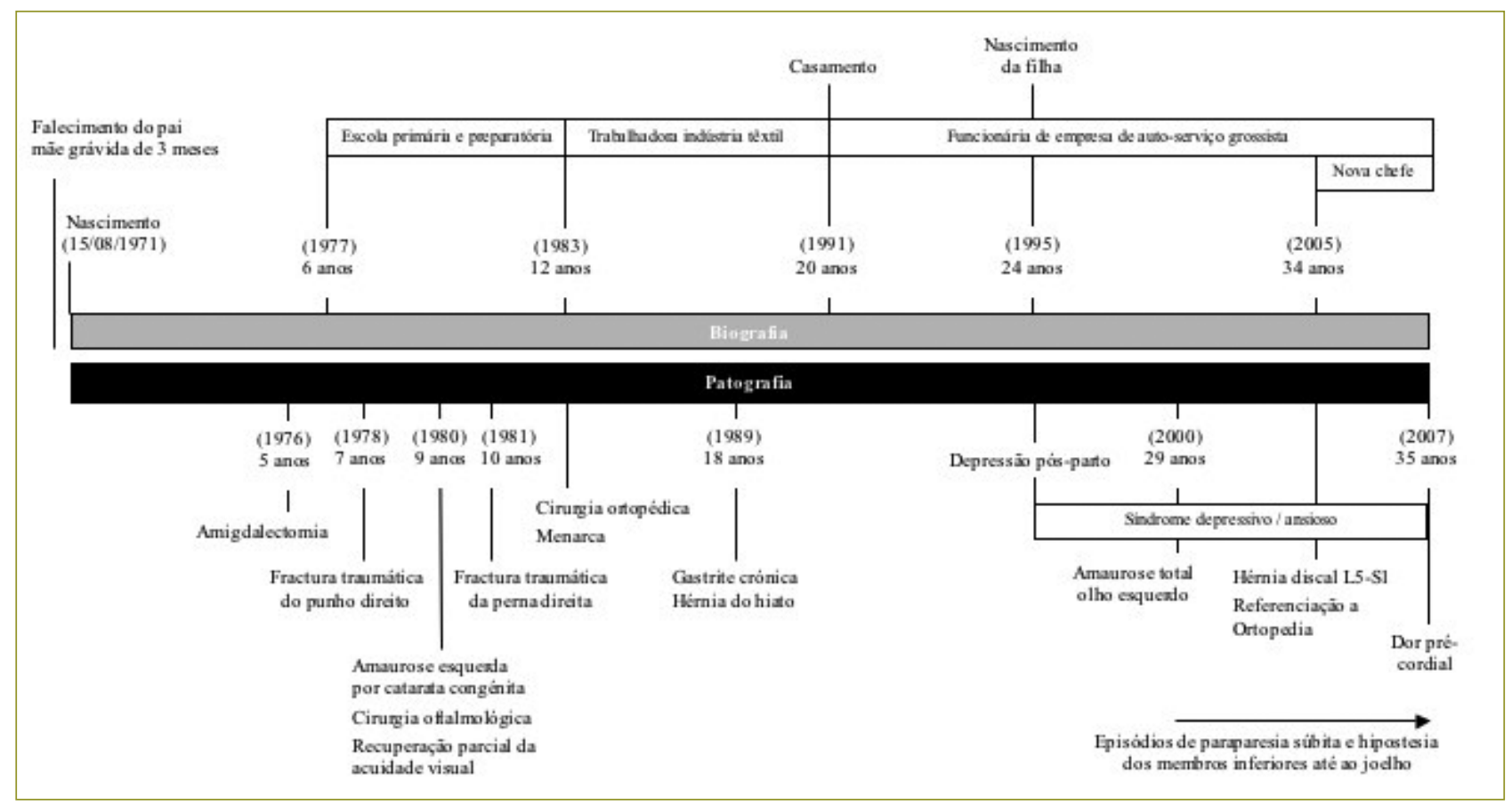

Figura 1. Biopatografia. 
to de episódios de lombociatalgia.

Problemas laborais desde 2005, altura em que mudou a sua superior hierárquica, com maior absentismo laboral.

Desde 2000, recorreu cinco vezes ao Serviço de Urgência (SU) por episódios de paraparésia súbita e hipostesia dos membros inferiores até ao joelho, sem factor desencadeante aparente, com recuperação total, «em algumas horas, após injecção intramuscular».

A 5 de Janeiro de 2007 foi transportada ao SU por episódio de dor pré-cordial com irradiação para o ombro esquerdo, ocorrido no local de trabalho. Terá alertado uma colega de trabalho que «ia perder os sentidos», tendo, em seguida, «desmaiado». No SU realizou exames auxiliares de diagnóstico, com resultados negativos, tendo alta, medicada com benzodiazepina em SOS.

\section{2 a 22 de Janeiro de 2007}

A doente é transportada ao Serviço de Urgência por quadro agudo de paraparesia, com anestesia dos membros inferiores, com nível aparente por D10, ficando internada no Serviço de Neurologia.

Durante o internamento, apresenta, ao exame neurológico: funções superiores normais, humor incongruente, com marcada indiferença emocional, paraparésia de grau 2 , inconsistente nas provas motoras segmentares e incongruente com a facilidade de transferência entre o leito e a cadeira de rodas, incapacidade de marcha ou sustentação em ortostatismo, hipostesia subjectiva dos membros inferiores, mas com menção de anestesia total táctil e álgica aquando da pesquisa de propriocepção, nível táctil e álgico por D12 pela face anterior do tronco, mas L1-L2 pela face posterior (ambos inconsistentes com o nível avaliado no Serviço de Urgência por D10). À excepção da amaurose esquerda, o restante exame era normal, nomeadamente o tónus muscular, os reflexos osteo-tendinosos e cutâneo plantar e a função dos esfíncteres.

Realiza punção lombar, estudo analítico com hemograma, velocidade de sedimentação, função hepática, função renal, ionograma, serologias para vírus da imunodeficiência humana, prova serológica não treponémica VDRL (Veneral Disease Research Laboratory), função tiroideia, doseamentos de vitamina B12 e ácido fólico, enzima conversora da angiotensina e pesquisa de autoanticorpos. Todos os resultados são negativos.
Efectua ressonância magnética do neuroeixo, que evidencia discopatias múltiplas e hérnia discal lombar L5-S1, com eventual compromisso radicular L5 e S1 direito, mas não justificativos do quadro clínico; sem alterações de sinal medular.

Ensaia-se injecção intra-muscular de placebo, sem sucesso.

Quando confrontada com a hipótese de provável etiologia psiquiátrica, não contesta e admite como «bem possível». Refere ter sido «castigada» no emprego, ao ser colocada num guichet de $2 \mathrm{~m}^{2}$, em pé, sem possibilidade de se sentar, durante todo o horário laboral. Relata que, na véspera da admissão no serviço de urgência, chegou a casa " com as pernas muito cansadas» e que, no dia seguinte, quando acordou, «já não as conseguia mexer».

Assim sendo, tratava-se de um quadro de paraparesia recorrente, com exame neurológico incongruente e indiferença emocional, sem evidência de lesão medular estrutural, interpretado como um episódio conversivo, no contexto de stress laboral. Tem alta, sem melhoria da sintomatologia, orientada para consulta de Neurologia e para o seu MF, com sugestão de referenciação para Consulta de Psiquiatria e programa de Fisioterapia em ambulatório.

\section{3 de Janeiro de 2007}

O marido comparece a consulta não-programada com o MF. Acentuadamente ansioso, relata o internamento da esposa e fornece informação do serviço de Neurologia. Refere que, desde há dois anos, a esposa tem tido problemas com a nova chefe e que, desde há dois meses, tem sido «castigada sem motivo justo». Mantém, de momento, paraparesia, com necessidade de cadeira de rodas. Nega instalação de novos sintomas desde a alta. Faz-se referenciação a Consulta de Psiquiatria e Consulta de Medicina Física e Reabilitação. Passa-se Certificado de Incapacidade Temporária. Agenda-se nova consulta.

\section{2 de Fevereiro de 2007}

A doente vem a consulta programada com o MF, em cadeira de rodas, negando melhoria sintomática. Refere que, desde o internamento, está «mais ansiosa, mais irritável e mais sensível». Já iniciou fisioterapia, em duas sessões de três horas por semana, afirmando que o fi- 
siatra «é muito bruto», «puxa muito» e que até a «magoou no pé» ao fazer o exercício, mas que gosta muito das sessões.

Quando questionada sobre as circunstâncias familiares, sociais e laborais no período prévio ao início dos sintomas, a doente refere uma situação de conflito constante com a sua chefe, que adjectiva de «mal-educada, arrogante, prepotente e má», que a está sempre a criticar e que lhe grita com frequência. Esta situação agravou-se nos dois meses anteriores ao internamento, quando foi «castigada», tendo de permanecer oito horas por dia num espaço pequeno, na posição erecta, com as mãos atrás das costas, referindo dores intensas nos membros inferiores, no final do período de trabalho. Refere que se sentia desanimada, triste, sem vontade de ir trabalhar, sem vontade de realizar as suas actividades sociais e lúdicas habituais com as amigas. Refere, também, insónia inicial e diminuição do apetite. Relata, ainda, o episódio de dor pré-cordial no local de trabalho, que motivou a sua ida ao serviço de urgência, negando a sua recorrência.
Considera que, desde o internamento, tem recebido apoio das suas colegas, que lhe contam que a sua chefe as questiona, várias vezes, pelo seu estado de saúde. Em termos de dinâmica familiar, refere que a filha está mais triste, mais dependente, procurando passar mais tempo com a família. O relacionamento conjugal melhorou, afirmando que valoriza mais o marido e o seu papel na família.

Descrevem-se, de seguida, os resultados dos métodos de avaliação familiar, aplicados com o objectivo de avaliar a estrutura da família, padrão de funcionamento, padrões relacionais, recursos psicossociais, desenvolvimento e risco familiar. ${ }^{7-8}$

\section{Genograma e Psicofigura de Mitchel}

O agregado familiar é constituído por três pessoas: a doente, o marido e a filha de 11 anos de ambos (Figura 2). A doente nunca teve contacto com o pai, que faleceu com 26 anos, após acidente de viação, quando a mãe estava grávida de três meses. Nessa altura, passou a residir com a mãe e os irmãos na casa dos avós ma-

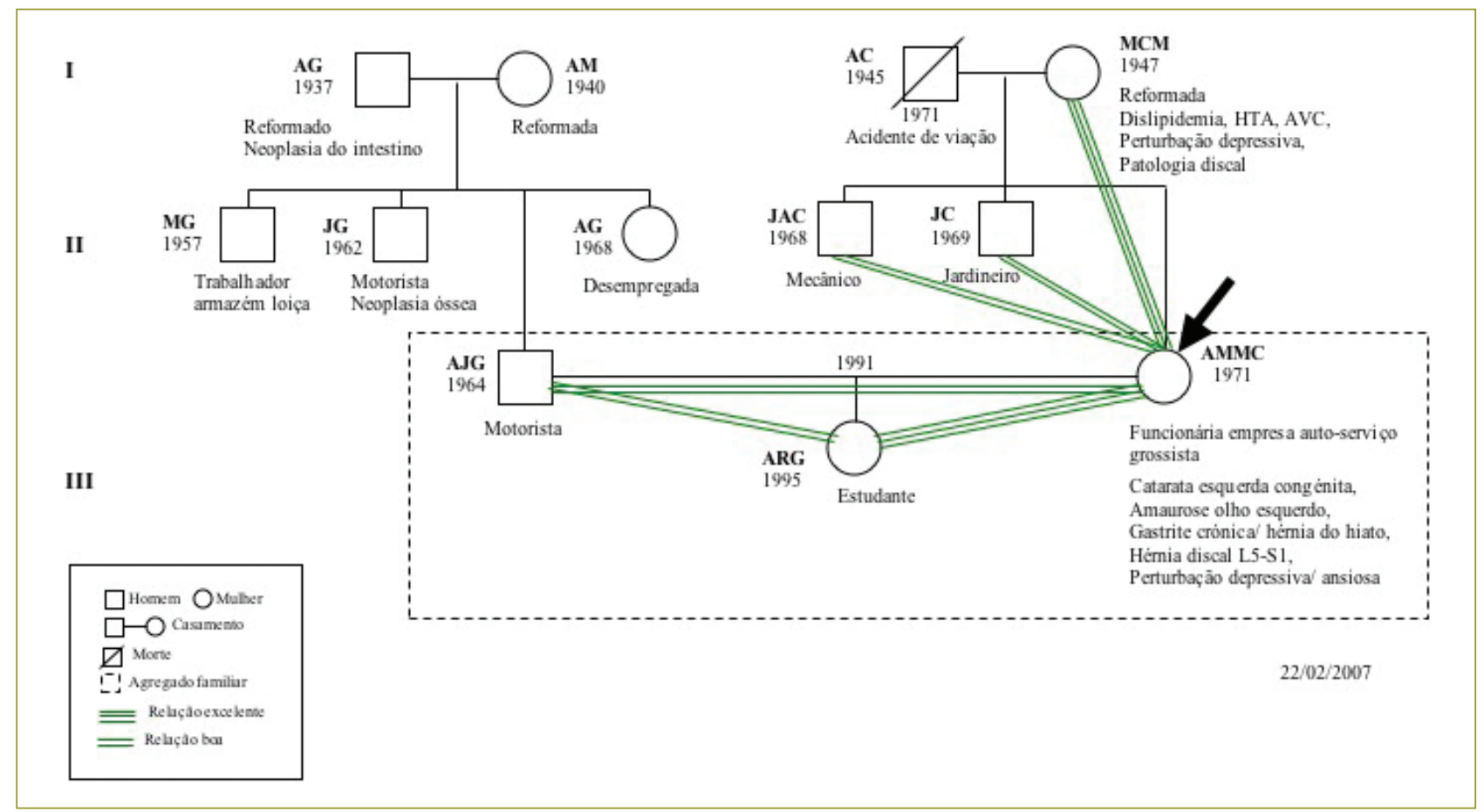

Figura 2. Genograma e Psicofigura de Mitchel.

Legenda: AVC: acidente vascular cerebral; HTA: hipertensão arterial. 
ternos. Parece existir um padrão de repetição familiar de patologia osteoarticular degenerativa e de síndrome depressivo.

Relativamente à Psicofigura de Mitchel, nota-se que a doente mantém um bom padrão relacional com os membros da família, em especial com a sua mãe, que sempre foi a sua figura de referência e apoio. Não parecem existir relações conflituosas entre o casal, nem com a filha de ambos. Desta forma, a família funciona como um grande recurso emocional e afectivo.

\section{Ciclo de Vida da Família}

Esta família nuclear encontra-se na fase IV de Duvall: família com filhos em idade escolar.

\section{APGAR Familiar}

Quando se aplica este questionário, obtém-se uma pontuação final de 8, o que sugere uma família altamente funcional. Assim, a doente refere estar bem adaptada à sua família, que lhe dá o apoio que necessita, dá-lhe atenção e partilha os problemas e afectos. No entanto, por um lado, sente-se, por vezes, um pouco limitada na sua liberdade e independência (refere que sempre foi muito autónoma e o marido nem sempre compreende este aspecto), por outro lado, gostaria de poder passar mais tempo com a família.

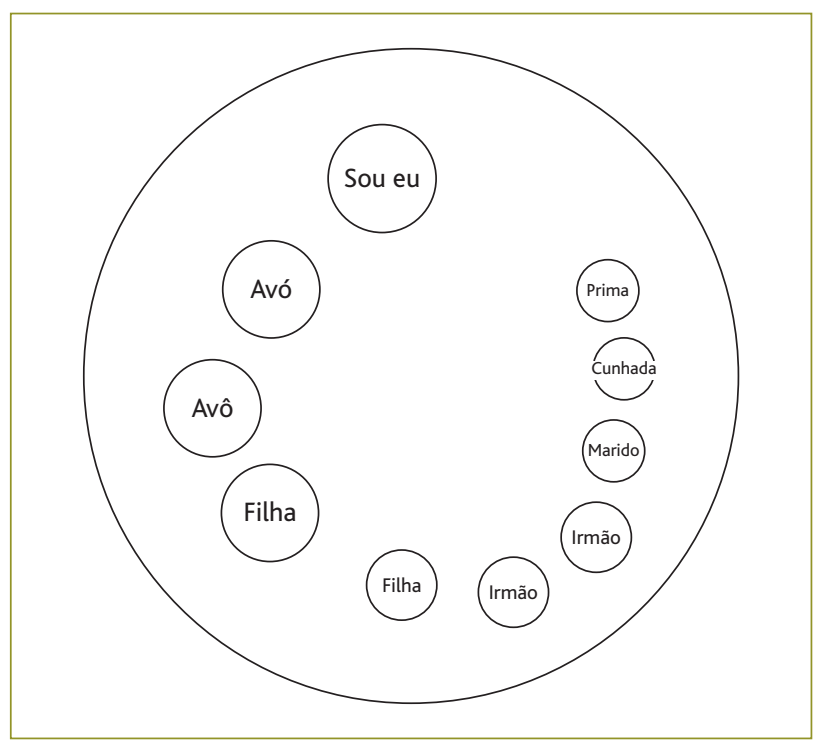

Figura 3. Reprodução do Círculo Familiar de Thrower efectuado pela doente.

\section{Círculo Familiar de Thrower}

Da representação gráfica do valor que têm para a doente as pessoas que lhe são mais próximas (Figura 3), realça-se o relevo emocional que a doente dá aos seus avós já falecidos, que faz questão de desenhar em segundo lugar e com um dimensão relativa considerável, referindo que sempre foram os seus modelos de acção e valores. Por outro lado, o marido foi representado depois da filha, da mãe e irmãos, ao que a doente argumenta que, em primeiro lugar, está a sua família, o seu suporte, que sempre conheceu e que «está acima de tudo».

Quando questionada se está contente com a representação que faz da sua família, responde que está muito satisfeita. Quando precisa de ajuda, recorre, primariamente, à sua mãe e a uma prima, que também representou.

\section{Escala de Readaptação Social de Holmes e Rahe}

Quando se aplica esta escala à doente, obtém-se uma pontuação de 167, considerando as alterações na dinâmica e responsabilidade laboral, nos hábitos pessoais, actividades sociais e recreativas referidas. De acordo com a escala, esta pontuação, em termos de risco de doença, traduz-se numa maior incidência de doenças em relação à população geral (enfarte de miocárdio, doença ulcerosa péptica, infecções, perturbações psiquiátricas).$^{8}$

\section{Escala de Risco Familiar de Segovia-Dreyer e Garcia-Gonzalez}

Quando se aplicam estas duas escalas de risco, verifica-se que não fornecem respostas coincidentes: pela Escala de Risco Familiar de Segovia-Dreyer trata-se de uma família de baixo risco, enquanto que, pela Escala de Risco Familiar de Garcia-Gonzalez, considera-se que se trata de uma família de médio risco, tendo em conta a solicitação em excesso dos cuidados do Centro de Saúde e o facto de a doente ser o centro das atenções da família, alterando as relações intra-familiares.

Ao exame físico, a doente apresenta-se colaborante, orientada no espaço e no tempo, auto e alopsiquicamente; humor eutímico; discurso lógico e coerente, débito normal; sem alterações da percepção ou da cognição. Sem ideação suicida. Restante exame com achados sobreponíveis aos relatos por neurologia.

Enfatizam-se os resultados negativos dos exames au- 
xiliares de diagnóstico e a noção que de vai melhorar. Passa-se Certificado de Incapacidade Temporária. Programa-se nova consulta.

\section{6 de Março de 2007}

Consulta de Psiquiatria. É alterada a medicação, atendendo à ausência de resposta à terapêutica e surgimento de novos sintomas (ansiedade e insónia inicial): suspende-se fluoxetina e inicia sertralina, $50 \mathrm{mg}$ ao pequeno-almoço, trazodona, $50 \mathrm{mg}$ ao deitar e cloxazolam, 2 mg ao deitar. Programa-se nova consulta.

\section{6 de Março de 2007}

Consulta programada com o MF. A doente já se mobiliza autonomamente, com o apoio de canadianas e já não tem queixas sensitivas. Mantém fisioterapia. Refere estar muito ansiosa, com insónia inicial, sensação de aperto no pescoço, episódios de amnésia retrógrada, gaguez e diminuição da acuidade visual.

Ao exame físico já não tem défices sensitivos, e apresenta défices motores inconsistentes após manobras de distracção. É capaz de sustentação autónoma em ortostatismo por breves períodos.

Reforçam-se os progressos observados. Passa-se Certificado de Incapacidade Temporária. Programa-se nova consulta.

\section{0 de Março de 2007}

Consulta de reavaliação de Neurologia. Apresenta défices motores inconsistentes após manobras de distracção. É capaz de marcha e sustentação autónoma em ortostatismo quando precipitados; já sem défices sensitivos; sem outras alterações à excepção da amaurose esquerda. Tem alta da consulta.

\section{6 de Abril de 2007}

Consulta programada no MF. Já se mobiliza sem o apoio de canadianas. Refere manutenção da insónia, ansiedade e irritabilidade. Já teve novas consultas de Psiquiatria, com necessidade de consultas não-programadas devido aos sintomas descritos. Mantém fisioterapia. Questiona-se funcionamento familiar, ao que a doente salienta o apoio recebido, nega situações de conflito conjugal ou com a filha. Objectivamente sem défices motores ou sensitivos. Prorroga-se o Certificado de Incapacidade Temporária. Marca-se nova consulta.

\section{5 de Maio de 2007}

Consulta programada no MF. Sem novas queixas. Mantém fisioterapia e seguimento em Psiquiatria. Refere que, no mês seguinte, deseja recomeçar a trabalhar. Sem alterações ao exame físico. Prorroga-se o Certificado de Incapacidade Temporária. Agenda-se nova consulta. Sugere-se marcação de consulta para a filha de forma a avaliar o impacto e a adaptação à patologia da mãe e à consequente alteração da dinâmica familiar.

\section{COMENTÁRIO}

As perturbações somatoformes são caracterizadas pela presença de sintomas físicos que sugerem uma condição médica geral, mas que não podem ser completamente explicados por uma causa orgânica, pelos efeitos directos de uma substância ou por outra perturbação mental. Os sintomas não estão sob controlo voluntário, não são intencionais e causam sofrimento ao doente ou prejuízo nas suas actividades profissionais, sociais ou em outras áreas importantes. ${ }^{9}$

De acordo com a American Psychiatry Society, as perturbações somatoformes subdividem-se em:

- perturbação de somatização,

- perturbação somatoforme indiferenciada,

- perturbação dolorosa,

- hipocondria,

- perturbação dismórfica corporal,

- perturbação de somatização sem outra especificação,

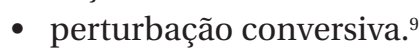

Relativamente à perturbação conversiva, a sua característica essencial consiste na presença de sintomas ou défices que afectam as funções motoras voluntárias ou sensoriais, sugerindo uma doença neurológica ou outra condição médica geral. Considera-se que existem factores psicológicos associados ao sintoma ou défice, através de um juízo baseado na observação de que o início ou exacerbação destes são precedidos por conflitos ou outros factores de stress. ${ }^{9}$

Na população geral verifica-se uma prevalência desta patologia que varia de 11:100.000 a 300:100.000. ${ }^{9}$ Após consulta no MF, a maioria dos doentes é referenciada para Psiquiatria ou Neurologia, correspondendo, respectivamente, a 1 a $3 \%$ e $4 \%$ das referências do ambulatório para estes serviços. ${ }^{9-11}$ Ocorre, mais frequentemente, no sexo feminino (prevalência variando de 2:1 
a 10:1), em geral entre o final da infância e o início da idade adulta, sendo rara antes dos 10 ou depois dos 35 anos. É mais frequente em indivíduos residentes em áreas rurais, de meios sócio-económicos mais desfavorecidos e menos familiarizados com conceitos médicos e psicológicos. ${ }^{9,12} \mathrm{~A}$ forma do sintoma conversivo é influenciada pelas ideias culturais locais sobre os modos aceitáveis e credíveis de expressar o sofrimento. Cerca de dois terços dos doentes têm sintomas de outras perturbações psiquiátricas, sendo as mais frequentes as perturbações depressivas e da ansiedade. Outras perturbações associadas são as perturbações de personalidade: personalidade histriónica, anti-social e dependente, e perturbações relacionadas com o consumo de substâncias. ${ }^{4,9}$

No caso clínico apresentado, a doente provém de um nível sócio-económico médio, com baixa escolaridade, com patologia depressiva recorrente desde há 10 anos e que apresentava défices motores - paraparesia dos membros inferiores - e défices sensoriais - hipostesia dos membros inferiores. No entanto, os sintomas não se ajustavam a vias anatómicas conhecidas, não correspondendo a um défice num padrão de inervação motora ou sensorial. Reflectiam, no entanto, a conceptualização da doente quanto à sua condição e à sua própria anatomia. Para além disso, foram detectadas inconsistências nos défices em exames físicos repetidos e quando a atenção da doente era dirigida para outro ponto (por exemplo, na transferência do leito para a cadeira). Associadamente, e diminuindo a probabilidade de se tratar de uma doença orgânica, o restante exame neurológico era normal.

Esta sintomatologia pode ter estado relacionada (ou ter sido despoletada) por alterações nas condições de trabalho, com conflitos externos com a chefe, que se tinham intensificado nos dois meses anteriores e para as quais a doente não tinha adquirido mecanismos de $\mathrm{co}^{-}$ ping. Assim, os sintomas somáticos podem representar uma resolução simbólica deste conflito (conflito externo com uma figura de autoridade), reduzindo a ansiedade e permitindo à doente evitar uma actividade laboral que não lhe dava satisfação, esquivando-se do «castigo», e obter apoio, atenção e compreensão por parte da família, colegas de trabalho e da própria chefe.

Saliente-se, ainda, que, para além de uma relação temporal, há uma relação conceptual entre o factor ge- rador de conflito (castigo com obrigação de permanecer na posição ortostática) e os sintomas expressos (paraparesia). Pode-se, ainda, estabelecer uma associação entre a área atingida com uma condição médica que previamente afectou a doente (patologia discal - já causadora de sintomas nos membros inferiores).

Desde o aparecimento dos sintomas e ao longo da sua evolução, a doente aparentava uma relativa falta de preocupação face aos mesmos - trata-se de «la belle indifférence», que é uma característica típica, mas não específica, da perturbação conversiva. ${ }^{13}$ É, ainda, de notar que a doente já tinha, previamente, utilizado sintomas físicos (paresia e anestesia das pernas e dor précordial sem causa orgânica explicativa aparente) para expressar conflitos psicológicos, como se verifica frequentemente nestes casos. ${ }^{12}$

Para se estabelecer o diagnóstico de perturbação conversiva é, ainda, importante excluir doenças orgânicas, nomeadamente neurológicas, que possam explicar os sintomas ou défices. ${ }^{6}$ Por este motivo, uma história clínica e exame físico detalhados e vários exames auxiliares de diagnóstico foram realizados, com resultados negativos. No entanto, o diagnóstico deve ser visto como experimental e transitório, uma vez que a etiologia médica geral, para muitos casos de aparente perturbação conversiva, pode levar anos até se tornar evidente. A percentagem de diagnósticos incorrectos é de cerca de $4 \%$, sendo os diagnósticos médicos, posteriormente estabelecidos, mais frequentemente relatados, de epilepsia, perturbação do movimento e esclerose

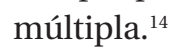

No processo diagnóstico foram, ainda, excluídas outras perturbações psiquiátricas, nomeadamente: perturbações factícias e simulação, perturbações psicóticas e outras perturbações somatoformes, com as quais se deve estabelecer o diagnóstico diferencial.,39

A abordagem terapêutica dos doentes com perturbações somatoformes é baseada em princípios similares e deve passar, essencialmente, pelo MF. ${ }^{15}$ Este é o profissional médico estrategicamente mais bem colocado para fazer uma abordagem somática e psicológica integrada, abordando os problemas individuais nas suas dimensões física e mental e enquadrando-os no contexto de circunstâncias familiares, redes sociais e culturais e circunstâncias domésticas e laborais.

Assim sendo, com vista a estabelecer uma relação 
terapêutica efectiva, é fundamental saber escutar o doente, com disponibilidade afectiva e intelectual. Dever-se-á adoptar uma atitude empática, de suporte e colaboração, para ajudar o doente a iniciar um trajecto para a compreensão da natureza da sua doença e de si próprio. É fundamental legitimizar os sintomas físicos perante o doente uma vez que, sendo a somatização um processo que não se encontra sob controlo voluntário, este pode interpretar uma explicação psicológica como uma acusação de estar a mentir ou a imaginá-los. Assim, é essencial que o doente sinta que o médico compreende as suas queixas e que não o julga ou culpa., ${ }^{3,15,16}$

Em relação ao médico, este deve estar preparado para alterar as suas expectativas relativamente aos objectivos e sucesso do tratamento. Os objectivos terapêuticos habituais, visando a cura, melhorando, ou, pelo menos, explicando os sintomas ao doente do ponto de vista patofisiológico são raramente tangíveis. Alternativamente, os objectivos terapêuticos deverão focar-se na modificação do comportamento do doente em relação à doença e no seu estado funcional. Objectivos iniciais razoáveis poderão ser diminuir a frequência de consultas não-programadas ou admissões hospitalares. Posteriormente, os objectivos poderão incluir ajudar o doente a adquirir mais controlo sobre si próprio e os seus sintomas, melhorar o seu papel social ou ocupacional ou ajudá-lo a comunicar sem ser através dos sintomas. O médico deverá evitar assumir toda a responsabilidade pela definição e alcance dos objectivos terapêuticos e deverá partilhar estas funções com o doente, numa verdadeira aliança médico-doente. .,15,16 $^{3}$

Para os doentes com perturbação conversiva, é recomendada uma abordagem conservadora e sugestiva, sendo mais útil conceber os fenómenos conversivos como sintomas e não como uma perturbação psiquiátrica per se. Transmitir aos doentes que se pensa que os seus sintomas sejam psicogénicos, resulta, frequentemente, num agravamento dos mesmos. É mais vantajoso enfatizar as boas notícias de que os resultados dos exames auxiliares de diagnóstico são negativos e explicar que os sintomas se irão resolver rapidamente e que está no preciso momento a começar a recuperar. Especificar uma sequência gradual de eventos que será de esperar numa recuperação pode fornecer sugestões sobre como o doente pode melhorar. ${ }^{2,3,17}$

Inicialmente, deverão ser marcadas consultas a cada duas a quatro semanas, mesmo se os sintomas estiverem estáveis. Estas marcações regulares de consultas breves (por exemplo: 15 minutos) visam diminuir a dependência de consultas não-programadas, devido a sintomas novos ou agravantes, evitando recompensar estes desenvolvimentos com consultas antecipadas. Para além disso, diminuem o medo do doente de ser abandonado pelo médico, que é uma razão importante de «doctor-shopping». Por último, permitem uma avaliação regular das queixas do doente, de forma a minimizar a não detecção de sinais físicos e evitando exames auxiliares diagnósticos desnecessários. ${ }^{3,15,16} \mathrm{O}$ foco da atenção deve ser, progressivamente, desviado dos sintomas físicos do doente, para o seu contexto psicossocial. A técnica BATHE (Backgroud, Affect, Trouble, Handle, Emphathy), por exemplo, constitui uma ferramenta útil para a exploração de factores psicossociais causadores de stress, proporcionando informação relevante para o médico, assim como um suporte valioso para o doente. ${ }^{17}$ Uma vez estabelecida uma relação terapêutica, a frequência das consultas poderá ser ajustada às presentes necessidades do doente.,3,15,16

No caso clínico apresentado, a doente manteve contacto frequente com o MF em consultas programadas, inicialmente mensais. Nessas consultas, que cumpriu de forma regular, a doente foi questionada quanto ao início, características, localização, duração, factores de alívio e exacerbação dos sintomas e a forma como estes passaram a afectar a sua vida. A doente foi encorajada a falar livremente dos seus problemas e preocupações e foram exploradas as suas relações familiares e laborais, tentando perceber quais os seus recursos psicossociais, os seus padrões relacionais, acontecimentos vitais e as suas repercussões subjectivas. Procurou-se estabelecer uma relação médico-doente de abertura, confiança, empatia e suporte. Os sintomas foram legitimados perante a doente, evitando abordá-los como uma perturbação psiquiátrica, mas reforçando a ausência de resultados positivos nos exames auxiliares de diagnóstico e, posteriormente, a melhoria progressiva dos défices.

Relativamente à terapia farmacológica, poderá ser necessário prescrever medicação para tratamento sintomático, que poderá contribuir para melhorar as queixas do doente e ser vista como um sinal de aceitação e compreensão dos sintomas. ${ }^{18}$ Nos doentes com pertur- 
bação depressiva ou ansiosa concomitante, o seu tratamento com antidepressivos e ansiolíticos melhora os sintomas da perturbação somatoforme. No entanto, especialmente no caso dos antidepressivos, dever-se-á começar com doses baixas e aumentar progressivamente, de forma a evitar efeitos laterais (especialmente no início do tratamento) que podem desencorajar o doente a cumprir o tratamento., ${ }^{3,16}$ Nos casos em que não há perturbação depressiva, o uso de antidepressivos (antidepressivos tricíclicos, antidepressivos anti-serotoninérgicos e inibidores selectivos da recaptação da serotonina) é moderadamente eficaz na melhoria dos sintomas somáticos $(\mathrm{OR}=3,4$ em relação ao placebo). ${ }^{18,19}$

No caso clínico, foi instituída terapêutica com sertralina, trazodona e cloxazolam, atendendo à patologia depressiva e perturbação da ansiedade co-mórbidas, e à insónia inicial referida.

Nas situações em que o diagnóstico é incerto (especialmente se existir suspeita de perturbação psiquiátrica major), quando não se consegue estabelecer um plano terapêutico, quando o plano estabelecido não está a ser eficaz e quando o doente deseja psicoterapia, deverá ser efectuada referenciação a Psiquiatria. ${ }^{15,20}$ Há evidência que demonstra a eficácia da terapêutica antidepressiva (já mencionada) e da psicoterapia. ${ }^{3,16,21} \mathrm{~A}$ forma mais comummente recomendada de psicoterapia é a terapia comportamental ou cognitivo-comportamental, que visa atingir a recuperação do doente, ajudando-o a modificar as crenças e comportamentos que perpetuam a doença. ${ }^{21}$

A referenciação à Consulta de Psiquiatria, no caso actual, foi realizada visando a orientação na elaboração de um plano terapêutico. Essa referenciação foi preparada cuidadosamente, de forma a que a doente a encarasse como uma possibilidade de ajuda suplementar e não como uma rejeição. ${ }^{15}$

A doente foi, igualmente, referenciada à Consulta de Medicina Física e Reabilitação, ${ }^{22}$ tendo realizado, posteriormente, várias sessões de fisioterapia com melhorias progressivas.

O MF foi o elemento coordenador da partilha de cuidados com as outras especialidades, numa aliança de trabalho permanente, que foi explicitada ao doente, e foi o elo de ligação entre os cuidadores e a doente e a sua família.
A perturbação conversiva tem, tipicamente, um início agudo (embora também possa ocorrer uma sintomatologia com aumento gradual) e, em $90 \%$ dos casos, os sintomas individuais têm curta duração. ${ }^{17}$ Em doentes hospitalizados, os sintomas geralmente apresentam remissão em 2 semanas. A recorrência é comum, ocorrendo em 20 a $25 \%$ dos indivíduos em 1 ano, sendo que uma única recorrência prediz episódios futuros. ${ }^{9}$ Os factores associados a bom prognóstico incluem um início agudo, a presença de um factor de stress claramente identificável no início dos sintomas, um curto intervalo entre o aparecimento dos sintomas e a instituição do tratamento, ansiedade ou depressão coexistente e inteligência acima da média. Sintomas de paralisia, afonia e amaurose estão associados com um bom prognóstico, ao contrário de tremores e convulsões. ${ }^{9,23}$ Os acontecimentos vitais e as circunstâncias sociais podem alterar dramaticamente o prognóstico, sendo que os doentes que sofrem mudanças nas suas circunstâncias e acontecimentos de vida, após o início dos sintomas, têm melhor prognóstico. ${ }^{10}$

Na doente apresentada, os sintomas tiveram um início agudo, mas não melhoram até à alta do hospital (passados 10 dias), persistindo por mais três meses, com melhoria lenta mas progressiva. Apesar disso, a doente tem um prognóstico favorável pela detecção precoce do factor desencadeante, pela perturbação depressiva / ansiosa associada, pela instalação precoce do tratamento e pela natureza dos sintomas físicos (paralisia). No entanto, trata-se de uma doente com manifestações prévias de sintomas conversivos e que pode ter maior probabilidade de recorrência, especialmente quando retomar a actividade laboral, caso ainda não consiga resolver o conflito externo com a sua superior hierárquica de uma forma mais saudável. Neste sentido, torna-se fundamental a manutenção da continuidade de cuidados e preservação da relação médico-doente para acompanhamento, escuta terapêutica e detecção precoce e tratamento de eventuais recorrências.

A família deverá ser envolvida neste processo, como elemento vital de suporte e estabilidade para a doente, apoiando, informando e esclarecendo, evitando conflitos e assegurando um padrão de funcionalidade. Especial atenção deverá ser prestada à filha da doente, uma vez que os sintomas conversivos são mais frequentes em parentes de doentes com esta perturbação, ${ }^{9}$ poden- 
do tornar-se numa forma de comportamento patológico que aprenda e adopte para resolução de conflitos internos e externos.

As perturbações somatoformes representam um dos motivos de consulta mais frequentes em Medicina Geral e Familiar, e também um dos mais desafiantes e difíceis de resolver.

Os modelos médicos tradicionais, focalizados na identificação e tratamento de doenças orgânicas, mostram-se desajustados e insuficientes, pelo que é necessária a aquisição de competências que permitam a correcta identificação e abordagem destes doentes. A inaptidão em reconhecer esta condição e em dar-lhe o correcto acompanhamento poderá conduzir a intervenções frustrantes, potencialmente perigosas, com custos elevados e que, geralmente, não identificam doença oculta e não aliviam o sofrimento.

Torna-se basilar uma abordagem centrada no doente, com integração dos aspectos psicossociais e biomédicos. A principal modalidade terapêutica é a relação médico-doente, baseada na legitimização dos sintomas, num ambiente de confiança, empatia, suporte e acompanhamento contínuo do doente (e, de uma forma mais abrangente, da sua família) em articulação com os diferentes níveis de cuidados do sistema de saúde.

\section{REFERÊNCIAS BIBLIOGRÁFICAS}

1. Serrano Cl. El paciente que nunca mejora. In: Sociedad Española de Medicina de Familia y Comunitaria. Guía de Actuación en Atención Primaria. Barcelona: SemFYC Ediciones; 2006. p. 475-8.

2. McCahill ME. Somatoform and related disorders: delivery of diagnosis as first step. Am Fam Physician 1995 Jul; 52 (1): 193-204.

3. Elder W. Somatoform symptoms and disorders. In: South-Paul JE, Matheny SC, Lewis EL, editors. Current Diagnosis and Treatment in Family Medicine. Ney York, NY: Lange Medical Books/McGraw-Hill; 2004. p. 631-9.

4. Servan-Schreiber D, Kolb NR, Tabas G. Somatizing patients: part I. Pratical diagnosis. Am Fam Physician 2000 Feb 15; 61 (4): 1073-8.

5. World Organization of Family Doctors (WONCA). A definição europeia de Medicina Geral e Familiar (Clínica Geral / Medicina Familiar). Lisboa: Edições Especiais APMCG; s/d..

6. Smith RC, Dwamena FC. Classification and diagnosis of patients with medically unexplained symptoms. J Gen Intern Med 2007 May; 22 (5): 685-91.

7. Agostinho M, Rebelo L. Família: do conceito aos meios de avaliação. Rev Port Clin Geral 1988; 32 (1): 6-18.
8. Caeiro R. Registos clínicos em Medicina Familiar. Lisboa: Instituto de Clínica Geral da Zona Sul; 1990.

9. American Psychiatry Association. Manual de diagnóstico e estatística das perturbações mentais. $4^{\mathrm{a}}$ ed. Lisboa: Climepsi Editores; 2002.

10. Halligan PW, Bass C, Wade DT. New approaches to conversion hysteria. BMJ 2000 Jun 3; 320 (7248): 1488-9.

11. Fink P, Steen Hansen M, Søndergaard L. Somatoform disorders among first-time referrals to a neurology service. Psychossomatics 2005 Nov-Dec; 46 (6): 540-8

12. Viederman M. Metaphor and meaning in conversion disorder. Psychosom Med 1995 Jul-Aug; 57 (4): 403-9.

13. Stone J, Smyth R, Carson A, Warlow C, Sharpe M. La belle indifférence in conversion symptoms and hysteria: systematic review. $\mathrm{Br} \mathrm{J}$ Psychiatry 2006 Mar; 188: 204-9.

14. Stone J, Smyth R, Carson A, Lewis S, Prescott R, Warlow C, et al. Systematic review of misdiagnosis of conversion symptoms and "hysteria". BMJ 2005 Oct 29; 331 (7523): 989-94.

15. Gordon GH. Treating somatizing patients. West J Med 1987 Jul; 147 (1): 88-91.

16. Servan-Schreiber D, Tabas G, Kolb NR. Somatizing patients: part II. Pratical management. Am Fam Physician 2000; 61 (5): 1423-8, 1431-2.

17. Roffman JL, Stern TA. Conversion disorder presenting with neurologic and respiratory symptoms. Prim Care Companion J Clin Psychiatry 2005; 7 (6): 304-6.

18. Sharpe M, Carson A. "Unexplained" somatic symptoms, functional syndromes, and somatization: do we need a paradigm shift? Ann Intern Med 2001 May 1; 134 (9 Pt 2): 926-30.

19. O'Malley PG, Jackson JL, Santoro J, Tomkins G, Balden E, Kroenke K. Antidepressant therapy for unexplained symptoms and symptom syndromes. J Fam Pract 1999 Dec; 48 (12): 980-90.

20. Yeung A, Deguang H. Somatoform disorders. West J Med 2002 Sep; 176 (4): 253-6.

21. Kroenke K, Swindle R. Cognitive-behavioral therapy for somatization and symptom syndromes: a critical review of controlled clinical trials. Psycother Psychosom 2000 Jul-Aug; 69 (4): 205-15.

22. Delargy MA, Peatfield RC, Burt AA. Successful rehabilitation in conversion paralysis. BMJ 1986 Jun 28; 292 (6537): 1730-1.

23. Crimlisk HL, Bhatia K, Cope H, David A, Marsden CD, Ron MA. Slater revisited: 6 year follow up study of patients with medically unexplained motor symptoms. BMJ 1998 Feb 21; 316 (7131): 582-6.

Conflitos de Interesse: não assinalados

\section{ENDEREÇO PARA CORRESPONDÊNCIA}

Paula Sofia Novais Gomes

Rua S. João, n 12, Monte Largo - Azurém

4800-064 Guimarães

E-mail: internos.infesta@gmail.com

TIm: 965487148 


\begin{abstract}
Introduction: In everyday practice, physicians are often faced with patients with symptoms for which an organic medical condition or a physiological explanation cannot be found. These patients represent a challenge for the Family Physician due to the use of inordinate amounts of health care resources, the persistent request for medical investigation, the difficult acceptance of a non-organic disease, leading to treatment resistance and the perpetuation of symptoms. The aim of this case report is to review and illustrate the role of the Family Physician in the management of patients with conversion disorder, namely in the diagnosis, psychosocial context, doctor-patient relationship, therapeutic goals, pharmacological treatments, articulation with other levels of care and follow-up.

Case description: It's described the case of a 35 years old woman, worker of an auto-service wholesale company, married, mother of one child, in stage IV of Duvall's family cycle, stage III of Graffar's socio-economical scale, with family Apgar of 8 points. She has a history of depression/ anxiety disorders. She presents to the emergency department with acute onset paraparesis and anaesthesia of the lower limbs, being admitted to the neurology department. After clinical evaluation, she is discharged with the diagnosis of conversion disorder in the context of stress in the workplace. Since then, the patient maintained frequent appointments with the Family Physician in an effective doctor-patient relationship, in articulation with psychiatric, neurological and physiotherapeutic care.

Comment: Considering the high prevalence of somatizing patients, the Family Physician must have the necessary skills for its proper identification and management. A patient-centred approach, considering the psychosocial context, should be followed. The primary therapeutic modality for the treatment of all somatoform disorders is the doctor-patient relationship, based upon the legitimization of the symptoms, in a comprehensive, supportive and continuous approach, articulating with other levels of care.
\end{abstract}

Key-words: Conversion Disorder; Family Medicine. 